\title{
THEORY AND PRACTICE OF PHILOSOPHICAL COUNSELING: A COMPARATIVE APPROACH
}

\author{
Borisov Sergey Valentinovich \\ Doctor of Philosophical Sciences (Advanced Doctor), Professor, South Ural State University of Humanities \\ and Education, South Ural State University (National Research University)
}

\begin{abstract}
The problem of our research is a complex of issues related to cultural and historical, theoretical, methodological and institutional aspects of the emergence and spread of such a new direction of modern philosophy as philosophical practice (philosophical counseling). The study is devoted to the development of the theory for the generalization, systematization and interpretation of extensive empirical material accumulated in the thirty-year history of this philosophical direction. On the basis of this theory historical and philosophical vision of the direction will be possible. The key condition of the research is the use of comparative approach, which establishes clear criteria for comparative analysis of philosophical concepts, basic concepts, forms and ways of philosophizing, used in philosophical practice. Our research provides an opportunity to define the basic principles, to build a typology of ideas, approaches, schools and trends of philosophical practice. This is the first comprehensive study to identify the role and place of philosophical practice in modern culture, which can become a reserve for new interdisciplinary philosophical research in this area.
\end{abstract}

Keywords: philosophy, philosophizing, philosophical practice, comparative approach, existentialism

\section{INTRODUCTION}

Philosophy as intellectual practice is presented, first of all, in classical philosophical works. Almost all the dialogues of Plato the practical use of knowledge is illustrated (maieutics of Socrates). On the one hand, in philosophy there is "naivety" of surprise and questioning, and on the other hand, metaphysical depth of questions and reflection over them. According to P. Hadot, the initial status of philosophy in culture is a system of spiritual exercises and spiritual practice, giving the opportunity to develop a holistic outlook and conscious (good) life (Hadot, 1995). "Naive" in form, but deep in content, is the position of Nikolai Kuzansky, who forms an idea of philosophical problems as "scientific ignorance". In particular, Nikolai Kuzansky creates "Book of ignorant" (Nikolai Kuzansky, 1979). Philosophical rehabilitation of "ignorant" appears here as a return to ancient traditions. Philosophical practice, in contrast to "school", academic philosophy, manifests itself actively in the genre of essays (aphorisms, maxims, reflections). It acts as the amount of worldly wisdom, common sense, sophistication, defining the "practical philosophy" of life of the individual (M.Montaigne, B. Pascal, F. La Rochefoucauld, J. La Bruyere).

Particular attention should be paid to the tradition of classical philosophical propaedeutics of the XIX century, which was reformed by the epistemology of pragmatism. Pragmatism, according to D. Dewey, was carried out with the Copernican revolution in the philosophical tradition, moving from the study of the problems of philosophers themselves to comprehending human problems (Dewey, 2004). In "Reconstruction in philosophy" Dewey puts forward the following requirements for philosophy: instrumentalism - philosophical ideas are oriented to practical problems; experimentalism - philosophy needs pilot test and self-criticism; genetic approach to the subject of philosophy as a process - the origin and development of philosophy can shed light on its current problems; contextualism - the content of philosophy should be regarded as an element of social and cultural situation.

Modern philosophical propaedeutics pays close attention to the specifics of children's thinking, including intellectual activity of children and adolescents in the sphere of philosophical practice. As for the philosophical practice of adults, all its numerous trends can be divided into two conceptual approaches: "therapeutic" and "developing". 
Since 1994 with a periodicity of approximately every two years, international conferences on philosophical practice and international seminars organized annually by representatives of various fields of philosophical practice are held. The materials of conferences and seminars serve as a theoretical and practical basis to trace all the trends in the exchange and development of key ideas, to characterize the main personalities, schools and currents of this philosophical direction (Lahav R., 2016a). It should be noted that the rich theoretical and empirical material accumulated over 30 years requires in-depth study and systematization, which allow to offer the general public literate, based on scientific criteria of orientation in this new philosophical direction in order to clearly distinguish all that related to it from what is a quasi-scientific and quasi-philosophical product of modern mass culture.

\section{METHODS}

The comparative approach we use involves careful consideration of significant cultural, historical, theoretical, methodological and institutional factors and conditions that influenced on the emergence and development of philosophical practice (counseling) in order to identify and evaluate options for building a theoretical generalization of empirical material. The comparative and historical method is the basis for working with articles and books on philosophical practice, websites, conference materials, as well as records of interviews and transcripts of consultations. Our focus is on philosophy as an ontogenetic process, so epistemology is exactly the methodology of our research. Phenomenological analysis began philosophizing, rooted in the structure of everyday practical knowledge, gives us the opportunity to interpret the theoretical content and methods of philosophical practice (counseling). These interpretations are carried out from the ontological hermeneutics point of view. Philosophizing in this way is considered as a way of being, which is carried out in the process of understanding. On this basis, it is possible to establish differences and similarities in the systems of philosophical practice. Methods and forms of philosophical practice (counseling), contributing to the process of generation and completion of ideas are considered by us in the context of a cultural and philosophical tradition. The empirical basis of our research, along with the sources listed above, is also a virtual critical discussion between various ideas, methods, personalities, schools and trends of philosophical practice, which, due to the comparative approach, gives a holistic view of the studied philosophical direction.

\section{RESULTS}

The results of our research are: a comparative and historical analysis of trends and schools of philosophical practice, the construction of a typology of philosophical practice; a comparative and historical analysis of Russian and world experience of philosophical practice; determination of philosophical practice features in relation to each approach presented in our typology, based on analysis of the literature and based on interviews or personal participation in individual or group counselling representatives of particular schools or directions of philosophical practice; approbation of the possibility of synthesis of approaches of philosophical counseling and practice of children and adults education, as well as practice of existential psychotherapy and humanistic psychology.

\section{TYPOLOGY OF MODERN PHILOSOPHICAL PRACTICE}

The analysis of various approaches rooted in modern philosophical practice allows us dividing them into three main groups (Lahav R., 2016b). Firstly, there are methods that can be described as "Approach oriented to solving problems" (Problem-Solving Approach). These methods help people to solve specific problems of their lives and to overcome them: dissatisfaction with work, marital relationships, low self-esteem, etc. In this respect they are similar to the methods of psychotherapy. Another approach related to this helps people develop thinking skills using which they can deal with personal problems and difficulties in the future. The emphasis of this "Approach oriented on thinking skills" (Thinking Skills Approach) is made on improving the tools for thinking, rather than on solving specific problems. The third group of philosophical practices, which can be named as "Approach oriented on self-development" (Development Approach), is aimed at enriching life with meaning and wisdom, depth and fullness.

On the "technology" of these approaches implementation, we distinguish two groups. At first, there are philosophical practices in which critical thinking prevails. Proponents of this "Approach based on critical thinking" (Critical Thinking Approach) believe that the whole philosophy is, in fact, the desire for rational analysis. In this regard, the methods of philosophical counseling should be based solely on the tools of logical thinking, such as reasoning, logical consistency, analysis of concepts, the identification of hidden prerequisites,

Submit Date: 10.01. 2018, Acceptance Date: 23.02.2018, DOI NO: 10.7456/1080MSE/119

Research Article - This article was checked by Turnitin

Copyright (C) The Turkish Online Journal of Design, Art and Communication 
etc. An alternative to critical thinking is that can be called an "Approach based on wisdom "(Wisdom Approach). Here the main attention is paid not to critical thinking (although it is also important), but to the depth of philosophical ideas. Its main task is not to analyze ideas, but to "finish" them for a deeper understanding of life.

Philosophical counseling. This is a form of individual or group work, which is a series of meetings organized and directed by a consulting philosopher. Outwardly, this may resemble one of the types of psychotherapy, in particular, existential psychotherapy (or Dasein analysis). The philosophical "filling" of this therapy is that, firstly, its basis, which gives an idea of the structure of the person, is the ontological principles of existential philosophy, not the biomedical or psychometric characteristics of the person used in psychological science. Secondly, the consultation procedure itself involves working with philosophical categories, in the light of which there is an understanding of certain ideological problems of the client (Borisov S.V., 2016). Often certain philosophical texts are the material for the work that help the client to carry out the necessary reflection on the specific and particular manifestations of his "philosophical disease". The phrase "philosophical disease" is not a metaphor, it is a real state of human existence in the world of everyday life, characterized by acute sensitivity to the "call of being", associated with the fear of death, social isolation, freedom and meaninglessness of life (Holzhey-Kunz A., 2014). Thus, it is reasonable to assume that the "philosophical disease" is treated by philosophical methods, which represent a semblance of ancient practices of "taking care of oneself", "collecting oneself" in the conditions of faceless structures of everyday life.

Philosophical companionship. This form of philosophical practice is a group of partners engaged in joint philosophical contemplation of certain aspects of ideological problems by phenomenological reduction method. The main condition of the philosophical companionship is a deep focus on the "pure" experience, which can be obtained on the basis of the meditative state, which puts "in brackets" all the automatism of thought and speech of external everyday experience. Concentration on this experience is carried out by method of slow reading of fragments of these or those philosophical texts containing the finished ideas on the contemplated problem. The expression of own ideas is carried out in unison with the read text, its main concepts are distinguished from which the general "map of ideas" is constructed by joint efforts of group, supplemented with the concepts or images arising in space of "pure" experience of each participant of the group. This philosophical companionship is not an intellectual club or a scientific community. The purpose of the group work is to help collectively clarify philosophical ideas through joint efforts, rather than competitive procedures of intellectual debates and scientific disputes. The work of the group members resembles the actions of musicians in a single orchestra, achieving harmony and purity of performance and beauty of harmony (Lahav R., 2016c).

\section{“THERAPEUTIC APPROACH” IN MODERN PHILOSOPHICAL PRACTICE}

"Therapeutic approach" focuses on the work with a particular psychological problem, which becomes the subject of individual or group counseling. As part of this approach, there is an extensive empirical material that requires its generalization, analysis and systematization, which allows talking about trends in the synthesis of philosophical practice and psychotherapy. As a rule, such synthetic zones are research and practice in the field of humanistic psychology, existential psychotherapy, Gestalt therapy, various forms of art therapy and coaching. In this regard the greatest scientific interest are studies by G. Achenbach (Achenbach, G.B., 1984; Achenbach G.B., 2006; Achenbach G.B., 2010) and the activities of the International Group for Philosophical Practice (IGPP) in Germany, Austria and Switzerland, the activities and publishing projects of the L. Marinoff also should be noted (Marinoff L., 1999; Marinoff L., 2002; Marinoff L., 2004) and American Philosophical Practitioners Association (APPA), activities of Society of Practical Philosophy (SPP) in the UK and the Russian Association of Psychologists and Philosophers "Existential and Humanistic Psychology" (P. Kochyunas, I. Glukhova, T. Shchyttsova, V. Kagan, V. Andryushin).

Firstly, the philosophers-practitioners within the framework of this approach say that everyday life remains at a superficial level, which does not reflect the fullness of human existence. Secondly, according to these philosophers, there is an alternative way of human existence. Thirdly, they show that it is very difficult to move from our shallow state to the state of completeness of being. Our natural tendencies do not lead us to this automatically; overcoming these tendencies is a big problem. What we need is a complete transformation 
that will transform every aspect of our existence - our emotions, behavior, thoughts, and attitudes, from the smallest to the most significant.

We found out that there are two common themes for these and similar "transformative approaches". Firstly, these approaches describe our superficial state, controlled by rigid patterns, namely patterns of behavior, thoughts, desires, and emotions. These patterns are the result of powerful psychological or social mechanisms that are at work within us, which leads to limited ways of being that separate us from the fullness of real being. Secondly, all of these transformative approaches assume that the state of completeness goes beyond these laws and cannot be bound to any fixed structure. They compare this condition with the release. The following terms are used: freedom, spontaneity, flow, creativity, uniqueness, authenticity, individuality, openness, expansiveness. Interestingly, this release is described only indirectly, without accurate analysis. A poetic metaphor or an appeal to personal experience are often used. This is not surprising, because patterns and mechanisms have a fixed structure and can be analyzed directly and accurately. On the contrary, what goes beyond patterns contradicts analysis because it goes beyond any fixed formula.

\section{“DEVELOPING APPROACH” IN MODERN PHILOSOPHICAL PRACTICE}

"Developing approach" focuses on achieving understanding and completion of ideas about life, checking them for validity using a variety of intellectual means and building the path of further spiritual growth. That is, in general, individual and group work is carried out not with certain psychological problems and life situations, but with ideas about life, opportunities for building a holistic worldview are analyzed and expanded. As part of this approach the material of the Institute of Philosophical Ppractice led by O. Brenifier requires a theoretical generalization (France) (Brenifier O., 2018; Philosophy a School of Freedom, 2007). These philosophical practices are aimed at the formation of critical thinking skills, the ability to express their thoughts, to argue. A different trend emerging in the framework of the "developing approach" associated with the activities of the community Philo-Practice Agora should also be noted (R. Lahav, K. Zavala) (Lahav R., 2016c), which essence is to achieve the principles of philosophical partnership, undergoing individual or joint experience of ideological transformation and completeness of ideas.

"Developing approach" in philosophical practice, as a rule, is named the approach of critical thinking (critical thinking approach). This approach provides a variety of forms in a variety of areas, in particular, business coaching is very popular. Thus, the French philosophical practitioner O. Brenifier is actively working with the staff of a number of major Russian state corporations (Brenifier O., 2013). In higher education practice, unlike British and American universities, where there is a course of critical reasoning, in Russia there is no special course directly aimed at the development of critical thinking, which can be compensated by the use of methods of philosophical practice in the teaching of the basic course of philosophy. For example, such approach in Russia is implemented in Volgograd State University by the philosopher-practitioner A.I. Makarov, who uses the method of Socratic dialogue (Makarov A.I., 2012).

This form of philosophical practice is based on the principles of working with internal and external speech. Philosophers understand quite well that a person's external speech does not always correspond to what he thinks, moreover, because external speech is mostly automatic, firstly, certain statements of a person may not express any thought at all, but entirely relate to the manifestations of his emotional state; secondly, often a person resorts to external speech in order to disguise, hide real thoughts about himself, about others or about the situation, involuntarily misleading himself and others. Therefore, the philosopher's task is "to reconcile" the interlocutor with his own speech, that is, to open for him a reflexive plan for analyzing his speech statements to discover those hidden thoughts that the external speech masks. This philosophical practice is very effective both to clarify the meaning of the concepts used in external speech and to clarify the meaning of the problems arising in certain situations that prevent a person from solving certain life tasks.

\section{SYNTHESIS OF APPROACHES OF PHILOSOPHICAL COUNSELING AND PRACTICE OF EDUCATION OF CHILDREN AND ADULTS}

The authors and adherents of the world famous program "Philosophy for children" (M. Lipman, E. Sharp) believe that "children's philosophizing" is, first of all, an effective lever for the development of critical, reflective, research thinking. They also believe that the child is able to think abstractly, and perceptive and affective perception of the world is impossible without "higher order thinking", so philosophical reasoning is

Submit Date: 10.01. 2018, Acceptance Date: 23.02.2018, DOI NO: 10.7456/1080MSE/119 
quite accessible to the thinking of children (Lipman M., 2017). American researcher G.B. Matthaws believes that naive philosophy of childhood helps to understand better the essence of philosophy (Matthaws G.B., 1994). We tested the possibility of synthesis of approaches of philosophical counseling and practice of education of children and adults. In the course of the analysis of the materials of group philosophical counseling of children who study at Motessori-center "School of mind", we established that if proper attention is paid to the children's interpretations of everyday life, it is possible to find some universal grounds of philosophizing, integrated in the process of child mastering (appropriation) the symbolic reality of culture (Borisov S., 2013). Naive philosophy of childhood is a fundamental mental and existential human experience.

Now, some facts about the practice of adult education. Systematization of the material of introductory courses "Theory and practice of philosophical counseling", which we conducted for educators, its critical analysis, allowed us developing recommendations about the features, opportunities and prospects of using the experience of philosophical practice. In fact, the enculturation to the philosophical tradition should be guided by a simple principle, as in the chess game, a student will play with "white" pieces, not a teacher. That is, not a teacher, but a student will have the initiative and make the first move in the form of his own, very specific and private ideological problems and life issues that concern him personally. The task of the philosopherteacher will be to "bring" these problems to the philosophical level, in order to show how you can work with them in the field of abstract to understand the meaning and essence of the particular that worries the student "in life". Having carried out this work, the teacher will help the student to take a philosophical position in relation to his ideological problem, which may serve as a moment of its dialectical removal, will open for him a new life perspective and, of course, will be a significant factor in the enculturation to the philosophical tradition.

\section{CONCLUSION}

Our study suggests that one of the most relevant issues of modern philosophy is the question of the practical use of its enormous potential in the world of everyday life. Although philosophy has existed for a long time, philosophical practice is a new and very effective way of using philosophy to solve many of the daily and global problems faced by modern man, because at the heart of all these problems, by all accounts, are the problems of worldview. Philosophical practice at its core is a return of philosophy to its original status, which it had in ancient culture. And in this context, philosophy is not theories, not dogmas and not knowledge systems as a tribute to science, but a set of exercises for mental, intellectual and emotional "self-care".

Philosophical practice began to institutionalize relatively recently - in the 80-90ies of the last century. This is not surprising, as it was at the turn of the century there was a need to throw off the "scientific" mask from the philosophy, which is firmly grown to it, but it has never been natural. Philosophical practice (counseling), as a new direction, has its own "Socrates" and its "Protagoras" and even some "scholastic" differences, but these institutional aspects do not prevent to realize the main mission of this intellectual movement - to make philosophy an effective means to achieve a conscious and happy life.

\section{ACKNOWLEDGEMENT}

The article is prepared within the framework of the task \# 35.5758.2017 "Philosophical Practice as a New Paradigm of Modern Social and Humanitarian Researches" of the Ministry of Education and Science of the Russian Federation for the performance of government work in the field of scientific activity, and also within the framework of the RFBR project \# 17-33-00021 "Theory and Practice of Philosophical Counseling: a Comparative Approach".

\section{REFERENCES}

Hadot, P. (1995). Philosophy as a Way of Life: Spiritual Exercises from Socrates to Foucault, Malden, MA: Blackwell. Nikolai Kuzansky (1979). The books of ignorant, in Compositions in 2 volumes, V. 1, Moscow: Mysl. Dewey, J. (2004). Reconstruction in philosophy, N.Y.: Dover Publications. Lahav, R. (2016a). Philosophical Practice - Quo Vadis? in The Philosophy Clinic, ed. S. Costello, Cambridge Scholars Press. 
Lahav, R. (2016b). Stepping out of Plato's Cave: Philosophical Counseling, Philosophical Practice and SelfTransformation, 2 ed., Hardwick, Vermont: Loyev Books.

Borisov, S.V. (2016). Philosophical practice and existential psychotherapy: points of contact, in Sluchevsky reading: phenomenology and existential psychotherapy, St.-Petersburg: Costa, 88 - 102.

Holzhey-Kunz, A. (2014). Leiden am Dasein. Die philosophische Dimension psychischen Krankseins, in Philosophy and psychotherapy, St. Petersburg: Anatolia, 16-30.

Lahav, R. (2016c). Handbook of Philosophical Companionships, Hardwick, Vermont: Loyev Books.

Achenbach, G.B. (1984). Philosophische Praxis. Vorträge u. Aufsätze. Köln: Dinter.

Achenbach, G.B. (2006). Die Philosophische Praxis und die Zukunft der Psychotherapie, in Psychotherapie Forum, 14 (3), 131-135.

Achenbach, G.B. (2010). Zur Einführung der Philosophischen Praxis: Vorträge, Aufsätze, Gespräche und Essays, mit denen sich die Philosophische Praxis in den Jahren 1981 bis 2009 vorstellte. Eine Dokumentation. Köln: Dinter.

Marinoff, L. (1999). Plato, not prozac! Applying philosophy to everyday problems. N.Y.: Harper Collins. Marinoff, L. (2002). Philosophical practice. San Diego: Academic Press.

Marinoff, L. (2004). Thus spake settembrini: A meta-dialogue on philosophy and psychiatry, in Philosophy and Psychiatry, ed. by T. Schramme and T. Johannes. Berlin: De Gruyter, 27-49.

Brenifier, O. (2018). The Art of Philosophical Practice: Philosophical Attitudes, Socium i vlast, 1 (69), 73 79.

Philosophy a School of Freedom: Teaching philosophy and learning to philosophize. (2007). Paris: UNESCO Publishing.

Brenifier O. (2013). At seminars it is necessary to set the rhythm of thinking, Event-Marketing, 3, $218-223$. Makarov, A.I. (2012). Socializing function of philosophical practices (by the example of Socratic dialogue method), Bulletin of Volgograd State University. Series 7: Philosophy, sociology and social technologies, 3, $121-125$.

Lipman, M. (2017). Brave old subject, brave new world, in History, Theory and Practice of Philosophy for Children: International Perspectives, ed. by S. Naji and R. Hashim, L.; N.Y.: Taylor and Francis, 12 - 17. Matthaws, G.B. (1994). The Philosophy of Childhood, London: Harvard University Press.

Borisov, S. (2013). Naive philosophizing in the life of a child, NB: Philosophical researches, 11, $184-193$. 